\title{
Pedagogical uses of language focused on music to support linguistic wellbeing during emergency remote teaching
}

\author{
ISSN 2657-9774; https://doi.org/10.36534/erlj.2021.02.02 \\ Slađana Marić \\ University of Novi Sad, Faculty of Philosophy \\ sladjana.maric@ff.uns.ac.rs
}

\begin{abstract}
The aim of this research was to particularly focus on the intersection of language and music education, specifically pedagogical uses of language focused on classical music to support the linguistic wellbeing of students in an online learning environment. The research was conducted during a six-week course period of English as a foreign language lessons online with 30 second-year students of Music Performance at the Secondary Music School in Serbia during the remote teaching and learning period in 2020. The research implemented a fully online learning model. The qualitative results obtained from the research and presented in this paper, suggest that the course had an impact on the learners in terms of their overall positive reactions towards their language learning and linguistic wellbeing. Therefore, in the following period, the aim is to further research the intersections of language, pedagogy and the role of music on linguistic wellbeing in different language education contexts.
\end{abstract}

Keywords: digital resources, English in Professional Music Education (EPME), linguistic wellbeing, musicrelated vocabulary, teaching methodology.

\section{Introduction}

Language practitioners and researchers have increasingly focused their attention on the importance of both teacher and student psychological health and wellbeing, offering insightful research findings on creating opportunities for more positive relationships in teaching (online) lessons, avoiding possible personal and contextual stressors which can threaten wellbeing (leading to worrying rates of stress and burnout), developing skills for managing emotions and behavior, maintaining healthy body and mind during the school year, developing and improving motivation, energy levels and concentration in learning (Maclntyre, Gregersen \& Mercer 2020, Hessel et al. 2020, Mercer 2020, 2021, Shin et al. 2021, Resnik \& Dewaele 2021). However, in this paper, we contribute to a less researched intersection of linguistic wellbeing, specifically student linguistic wellbeing, English for Specific Purposes (ESP) research and pedagogical research literature. Defining wellbeing has proven to be very challenging, as it is regarded as a multidimensional, dynamic, and context-dependent construct (Sulis et al. 2021). In this article, the term "linguistic wellbeing" is referred to as a complex and dynamic system of developing, perfecting and strengthening skills of caring and responsibility for linguistic knowledge and use of language(s) in learning, education and different interactions between one's experiences across all life domains." During the lockdown period, from March 2020, the proposed or mandated measures of physical distancing, travel restrictions, prohibitions of large gatherings of people, have especially affected sectors of the arts, such as music, opera, ballet, dance, theatre, cultural and creative industries (Flew \& Kirkwood 2020). One of the main problems of forced lockdown restrictions was evident in the possible reduced emotional wellbeing of many worldwide. As noted by Sheppard \& Broughton (2020: 14) "childhood and adulthood are critical periods of life in which to establish participation in activities that are going to assist people to maintain their wellbeing and health into old age". According to 
Martínez-Castilla et al. (2021: 4), "perceived wellbeing through music performance or music listening is also positively related to individuals' ratings of music's importance in their lives" where lower emotional stability may be related to an emotional use of music, while the "music's importance is associated to perceived wellbeing through musical behavior". In the context of Music Arts education, schools have worked intensely to develop different strategies for adapting to the mandated rules and restrictions, all with the aim of providing continuous and quality education in various teaching and learning environments.

\section{Aims of research}

The aim of this research was to investigate the implementation of in practice specific language course materials focused on classical music, appropriate for the English in Professional Music Education (EPME) online course and how it contributes to (linguistic) well-being of students during the remote teaching and learning period in 2020.

\section{Research methodology \\ Research method}

In this action research, a qualitative data analysis approach of discourse analysis was applied. The Action Research "mode of inquiry is increasingly employed in SLE-oriented studies (Second Language Education) enabling interested, committed scholars to be proactively involved in their studies" (King, Lai \& May 2017: 22).

Action research is a teacher-designed and managed small-scale investigation, also known as "classroom-based action research", "educational action research" (Coghlan \& Brydon-Miller 2014, 103, 285), or "classroom research by a teacher" (McDonough, Shaw \& Masuhara 2013). As defined by Brown and Coombe (2015: 99), it is "an approach grounded in practical action (the action component) while at the same time focused on generating, informing, and building theory (research component)". Additionally, Wallace (1998: 16) states that it is very focused on individual or small-group professional practice, and can be defined as a "systematic collection and analysis of data relating to the improvement of some aspect of professional practice". In other words, action research is enacted with the main function "to facilitate the 'reflective cycle', and in this way provide an effective method for improving professional action" (Wallace 1998: 18) or "to deepen teacher professionalism" (Burns 2010: 166).

Action and research as behaviors come together in action research (AR) "through cycles of planning, action, observation and reflection that problematize (in a positive sense) issues, dilemmas or gaps that concern us in our teaching situations" (Burns 2010: 19). It empowers teacher-researchers in acquiring deeper insights and understanding of their practices (Burns 2013: 90), as it "involves iterations or cycles of problem identification, action planning, implementation, evaluation and reflection" (Coghlan \& Brydon-Miller 2014: 233), and not necessarily concerned with change (Nunan 1992: 18).

Based on the findings by Nunan (1992: 19) and Cohen, Manion and Morrison (2018: 440), for the research procedure, the following stages were chosen and applied: problem identification, planning an intervention, implementing the intervention, data collection, evaluating the outcome, reflection and teacher professional development.

\section{Data collection}

The objective of this research study was to provide opportunities for support to linguistic well-being of students by using in practice specific language course materials focused on classical music, appropriate for the English in Professional Music Education (EPME) online course, all in correlation with the national curriculum, needs and preferences of learners. Data collected in this research included 1) the Google Classroom materials created for teaching and learning (links, online videos, texts, tests, 
assignments, etc.), 2) online classroom posts and discussions, 3) audio recordings as homework activities by students, and 4) digital documents (written assignments, feedback, questionnaire/forms - test, quiz, surveys, posts, email messages, etc.) from the online class held in a Secondary Music education context (Vojvodina, the Republic of Serbia, Europe), during the remote teaching and learning period in 2020.

\section{Participants and setting}

Before the pandemic, the learning environment included the physical presence of a small or large class of students in the school environment, using traditional learning and teaching materials (books, notebooks, printed materials, board/whiteboard, CD player or other audio-visual media) in class, and with the emergency transition to online teaching and learning, the fully online coursebook compatible learning management system (LMS) and other non-General English activities created and used in the online classrooms environments. It is important to note that the stage of a research study aimed at the analysis of students' needs (necessities, lacks and wants) in learning was not conducted before the start of the course, due to the many reasons connected to the duration of the pandemic measures and limited time. Consequently, the prepared course was designed to offer new learning opportunities with available technologies and resources to satisfy the basic "need to actually enjoy the process of acquisition" (Hutchinson \& Waters 1987: 51), without any additional costs for the learning materials distribution or learning management system requirements, as students would require only an internet connection, google classroom and a device they feel comfortable working on (a tablet, phone or computer). Therefore, a need analysis is regarded as a continuing process, and the conclusions drawn will be constantly checked and re-assessed. Furthermore, the analysis of students' needs was eventually conducted "behind the scenes", during the course, by carefully monitoring student reactions during and after certain activities, in written comments and through shared ideas. In addition, at the end of the course through an "exit survey" students were given the opportunity to evaluate all the course materials as well as teacher preparedness, choice of materials and technology and performance in class. Students provided very open, sincere and positive feedback in this survey, commenting on all the aspects of the course: personal satisfaction with the course, teacher preparation, choice of materials, learning activities, tasks difficulty and technology used. To some researchers, the limitation of this survey might be that it was conducted in a specific setting, during the pandemic, and with a rather small group of students, to some, it may be a valuable insight in the context of research on linguistic wellbeing of students.

\section{Design and implementation timeframes and teaching contexts}

The first draft plan of a syllabus for EPME classes was created and piloted with the total of 33 secondary school students of Year 2, of Music Theory and Music Performance, at a Music School in the northern province of Vojvodina in the Republic of Serbia (Europe), in the previous school year of 2019/2020. In the context of a physical classroom, the digital media used was 1 ) a personal portable computer and speakers for video presentations and 2) a "non-obligatory" Google Classroom, for sharing in class the additional learning materials with examples of music specific content in English, for selfguided learning and development using mobile devices or personal computers. The general English learning was accomplished with a commercial coursebook pack approved by the National Ministry of Education. The curriculum part dedicated to the "language of the profession" included the learning activities (e.g. music scores for singing, text analysis, creative writing, etc.), created with the aim to establish important cross-curricular connections between the level of learning English (as a foreign language) and the knowledge in music-specific subjects in a particular year of studies. However, after March 2020, all the in-class activities were moved to a learning management system (LMS) of the coursebook pack for General English, while the already pre-established online classroom served as a 
bridge for offering additional activities, aimed at music content in particular, and offered a space for the main classroom communication and interaction.

\section{Language focused on classical music and aimed towards linguistic wellbeing of students}

For the following school year in September 2020, according to the national recommendations plan, all the language classes were offered online, while subject-specific lessons, such as instrument lessons, and smaller group lectures were held in a blended or physical classroom environment. A new group of 30 second-year students of the Music Performance Class had participated in a fully online English language learning environment. Lesson plans and activities were redesigned to the "new normal" of emergency remote online or distance learning. The lessons were held in a period of the first six weeks of the school year and were later followed by the commercial full general English language coursebook with another appointed teacher, due to internal staff reorganization actions enacted within the school, in the pandemic period. In terms of technologies, for the time duration of the EPME course, students were asked to use only their digital devices with the internet connection.

The main teaching and learning environment was the online classroom in which only the content for the lessons was published each week on the day of the lesson. The main working languages were both English and Serbian, with all the guidelines provided in both English and Serbian. Activities focused on language listening, reading, writing and speaking skills.

As the lesson format and timeframe has changed (from two classes per week to one 90 minutes lesson), this opened the space for introducing "thematic lessons". For the second grade of English for the students of Music Performance, the lessons in ESP Music were organized in the following order:

- Week 1: Introduction and obligatory initial test (in general English and basic music terminology, lessons 1\&2),

- Week 2: Music Arts and Music School: Music Instruments (lessons 3 \& 4),

- Week 3: Music Arts and Music School: Terminology in Music (Music Theory, Harmony, Music Analysis, (lessons 5 \& 6),

- Week 4: Music Arts and Music School: Music Culture/History of Music/Music Appreciation (listening to music)(lessons 7 \& 8),

- Week 5: Music Heritage and Institutions of Culture, Museums - "Listening to Music Today" (lessons 9 \& 10),

- Week 6: Music Education and Institutions of Music Culture (lessons 11 \& 12).

Even in the first obligatory initial test, taking place online (for the first time), the aim was not to stress students, having in mind the generally disturbing and uncertain times lived in 2020, and offer a completely unstandardized test with comprehension listening and writing tasks (basic language activities in general English with connection to the knowledge of basic music terminology). The understanding and application of the concept of linguistic wellbeing were mainly supported through the language activities focused on music in relation to:

- bringing satisfaction, joy or happiness to students learning in the online environments ("hedonic perspective" centered on the notion of happiness, conceptualizing wellbeing in terms of gaining pleasure and avoiding negative effects (Sulis et al. 2021: 2),

- strengthening confidence in foreign language use, specifically English focused on music (language for the profession),

- regulation of social anxiety (e.g. "reading aloud texts" as speaking activities with personalized indepth feedback to every student focused on strategies for further growth and development), and

- sensitivity and emotional vulnerability of students, as they were facing a different communication and learning context after a decade of traditional schooling experiences. 


\section{Findings}

Listening, reading and writing skills were practiced through the activities designed in the format of the Google Forms with linked videos within the form (at the specific position) different types of tasks, such as filling in the gaps, single or multiple choice answers and writing the answer. Additionally, for an introductory part, Padlet was used as a type of media offering students the possibility to write a short text and attach media. In terms of speaking skills, as students were not in the position to use the synchronous platforms for videoconferencing (lack of equal access to technologies, different timetables, location, etc.), to be able to communicate and interact with their voices being heard, they were encouraged to instantly use the chat for any type of question, comment or a form of a reply, as they would normally do in vocalized speech.

Why read-aloud longer texts? Firstly, as in the physical classroom, in online lessons students may demonstrate different levels of willingness to participate and practice their language vocalized performance. The "reading aloud" as an activity in online synchronous lessons would require time for both the readers and listeners and can be replaced by shorter speaking and reading activities. In this asynchronous online learning context, the "audience" was only the teacher. The social anxiety of "reading aloud", especially "sight-reading" a text, is therefore postponed to the moment of turning the record button "on". This allowed students to read, or not to read, the text before making the recording, as it can be easily heard in their pronunciation, intonation, tone and changes of "speed" while reading, the background noise, etc. Through the feedback analysis on the recordings of reading aloud longer texts, students were able to further work on their speaking and specific pronunciation skills, without the "pressure of other students as the audience" in class. This was evident, as students continued to practice, re-submit the full recordings or recordings of certain parts, and recorded their following reading tasks with greater confidence and success. Although this was an extremely time-consuming activity for the teacher, having in mind the total number of students and amount of material for carefully listening, teacher note-taking and providing clear and usable feedback to every student, it helped in establishing personal contact and trust. Most importantly, it encouraged students to engage in this type of vocal linguistic practice through the sound of their voice, as usually, musicians engage in transferring messages through the sound of music played or sung. These activities additionally (and unintentionally) revealed other information about the health of students, as the vocal apparatus was the main medium for the completion of this task.

For the generation of student participants, now aged 14 to 16 years, the use of cartoons, especially the chosen episodes, was a positive and joyful experience. Students were open to sharing their excitement and thoughts. They reported that they highly enjoyed these cartoons, as they were familiar with the characters and this "brought up some childhood memories", but rarely had seen these specific episodes, or vaguely remember some inserts (e.g. in most cases they have seen only the "The Cat Concerto"). Some of the chosen cartoons using themes or tunes from the music pieces from the Classical Music repertoire as the main narrator of the story, such as "Music Land" - Silly Symphonies, Disney (1935), and "Tom and Jerry: "Hollywood Bowl" (1950), "The Cat Above and the Mouse Below" (1964), "The Cat Concerto" (1947), were also used for practicing speaking skills, through retelling the plot of a story in a foreign language and presenting the roles of the characters (usually instruments or musicians - conductor, an opera singer, pianist, orchestra player). The cartoon with narration in English and themes or tunes from the music piece from the Classical Music repertoire, titled "Johann Mouse" (1952), was used for practicing language skills and strengthening confidence in foreign language use. Specifically English focused on Music were practiced by reading the story transcript (from the paper or within the following video) with musical accompaniment - "Tom and Jerry 'Johann Mouse' - Tomodachi 
Tokyo piano" (YouTube video ${ }^{9}$ ). Most of the instruments in these cartoons are illustrated through animated images with their unique sounds (sound of "real" instruments playing) and these episodes, therefore, are adequate for developing skills in music appreciation knowledge as well.

Figure 1: Screenshot of the video example for reading with musical accompaniment from the cartoon Tom and Jerry "Johann Mouse"

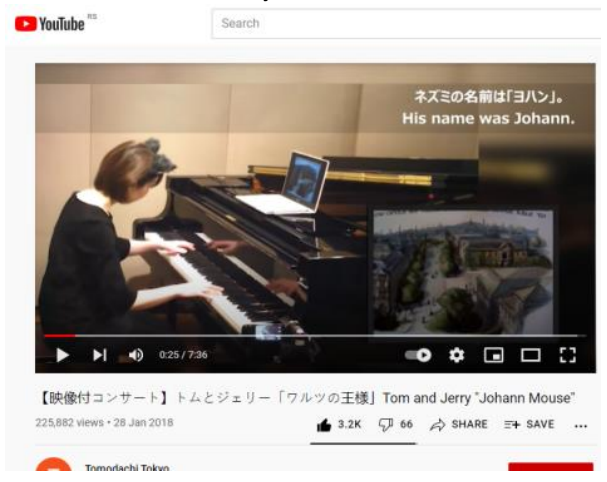

Furthermore, in the cartoon titled Tom and Jerry "Johann Mouse" one particular scene - "How To Play The Waltz In Six Easy Lessons by Johann Strauss", (duration less than a minute), offered different ideas for analysis, discussion and online debate (social interaction) in the English language as part of learning activities, connected to music education, music theory, music appreciation, music instruments presentations/illustrations, etc. In this scene, Tom teaches himself how to play the piano, following the guidebook, which consists of how to correctly play the first nine notes of "The Blue Danube" instantaneously becoming an accomplished pianist. The discussion included: 1) the visual presentation of the melody through six pages (Lesson I - Lesson VI), starting from one note, and ending with all nine notes in the last lesson, 2) how the keyboard piano keys and keystrokes do not correspond to the proper keys on the piano while playing this tune (not "the exact notes" from the score), 3) the overall process of music learning and performance, and 4) the river Danube and its connections to different cultures, languages and places.

As music may impact the overall wellbeing of an individual, one of the language learning activities included a piece from the Classical Music repertoire by the English composer Gustav Holst, titled The Planets, Op. 32 (1914 -1917), a seven-movement orchestral suite, with a joined wordless female chorus (in "Neptune"), representing "the power of the human imagination to see and hear the unknown" and "each of the seven movements of this suite is meant to express the ideas and emotions associated with a planet's effect on people and the world, as outlined in astrology" (Gale, Moore \& Ruddy 2013: 15). The work is scored for a large orchestra ${ }^{10}$. For the context of language learning and teaching, the choice of recorded video materials included the London Philharmonic Orchestra inserts from the series "Listening Guide to Holt's The Planets", as in these audio-visual video materials main abstract ideas are accompanied by concrete visual presentations that can become more understandable to learners, as the audience. When watching and listening simultaneously to these audio-visual materials, students were able to test their understanding of certain video content presented (audio and visual capacities being

\footnotetext{
9 https://www.youtube.com/watch?v=RocSo0pMJao

10 (Music specific vocabulary in English) Score instrumentation - Woodwinds: four flutes (2 piccolos and 2 flutes), two oboes, one cor anglais, bass oboe, three clarinets in $\mathrm{Bb}$ and $\mathrm{A}$, one bass clarinet in $\mathrm{Bb}$, three bassoons, one contrabassoon, Brass: six horns in $\mathrm{F}$, four trumpets in $\mathrm{C}$, two trombones, one bass trombone, one tenor tuba in $\mathrm{Bb}$ (often played on a euphonium), one tuba; Percussion: six timpani (two players), bass drum, snare drum, cymbals, triangle, tam-tam, tambourine, glockenspiel, xylophone, tubular bells. Strings: two harps, violins, violas, cellos, double basses; Keyboards: celesta, organ; (Full Score https://ia902803.us.archive.org/5/items/Holst_ThePlanets/Holst_ThePlanets.pdf )
} 
stimulated at the same time), having an opportunity for transferability across cognitive tasks, as a major challenge in learning both languages (verbal memory tasks) and music (non-verbal, and combined with verbal memory tasks). Music students generally through their education develop skills in listening to music, music dictation, singing and playing in smaller or larger groups, and these video materials provided an opportunity for enhancing specific language comprehension skills and memory by listening and watching relying on the many paralinguistic features like mimicking, gestures, postures, or attitudes that can assist them in grasping the meaning of the foreign language study material, and English language focused on music content (Table 1).

Table 1: Listening, reading and quiz "Holst's The Planets"

\begin{tabular}{|c|c|}
\hline $\begin{array}{l}\text { Listening, reading, quiz in Google Forms - "Holst's The Planets" (duration of all } \\
\text { videos is about } 30 \text { minutes in total) }\end{array}$ & Answers \\
\hline 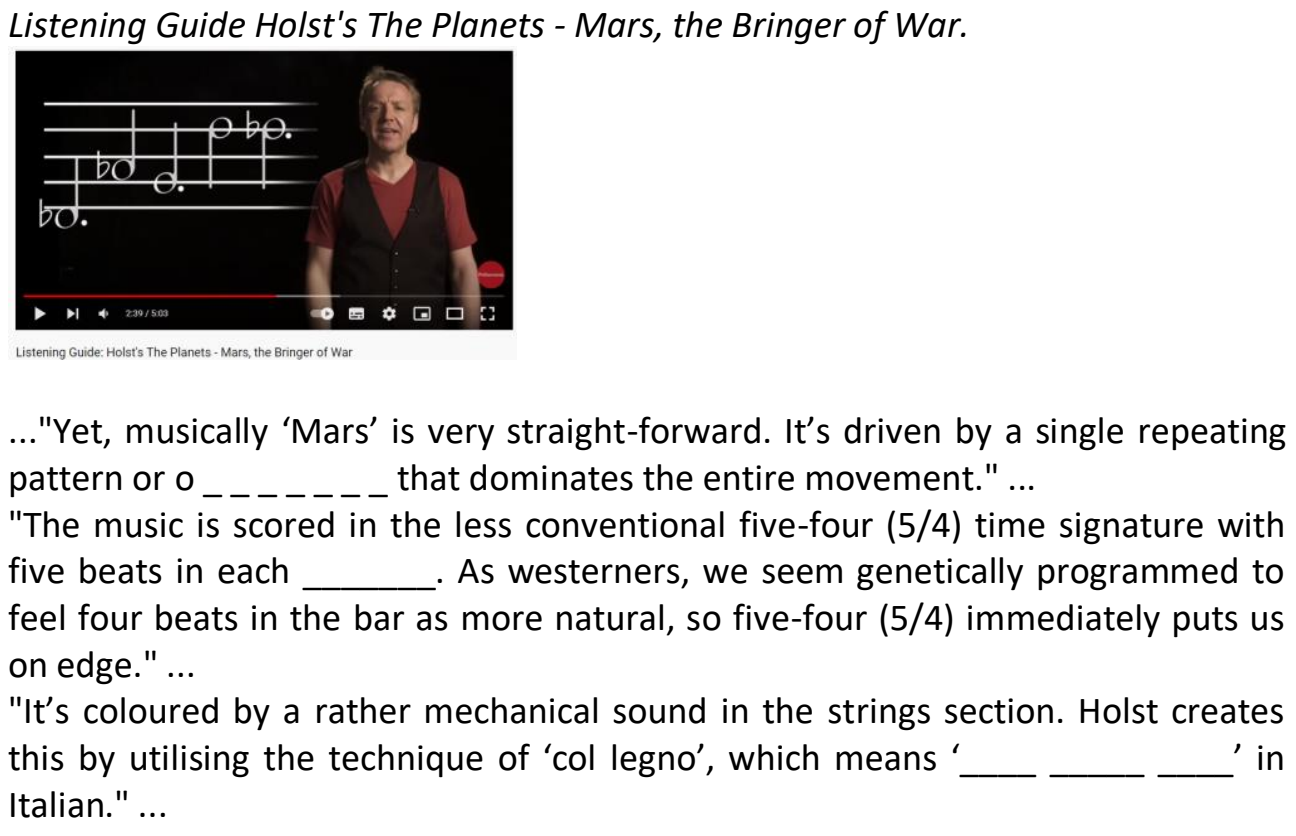 & $\begin{array}{l}\text { ostinato, } \\
\text { bar, } \\
\text { with the } \\
\text { wood }\end{array}$ \\
\hline $\begin{array}{l}\text { The Planets - Venus, the Bringer of Peace. } \\
\text { nowhere is that more evident than in his music for 'Venus'. } \\
\text { "But the most surprising thing isn't what Holst does, it's what he doesn't do. Look } \\
\text { at how empty the score is...Holst has one hundred musicians at his disposal, yet, } \\
\text { 'Venus' sounds more like intimate music. } \\
\text { "Much of the twinkling Holst refers to is created by the addition of two harps, a } \\
\text { glockenspiel and celeste in the orchestra. Celeste was invented in France towards }\end{array}$ & $\begin{array}{l}\text { composer, } \\
\text { chamber, } \\
\text { orchestration }\end{array}$ \\
\hline
\end{tabular}




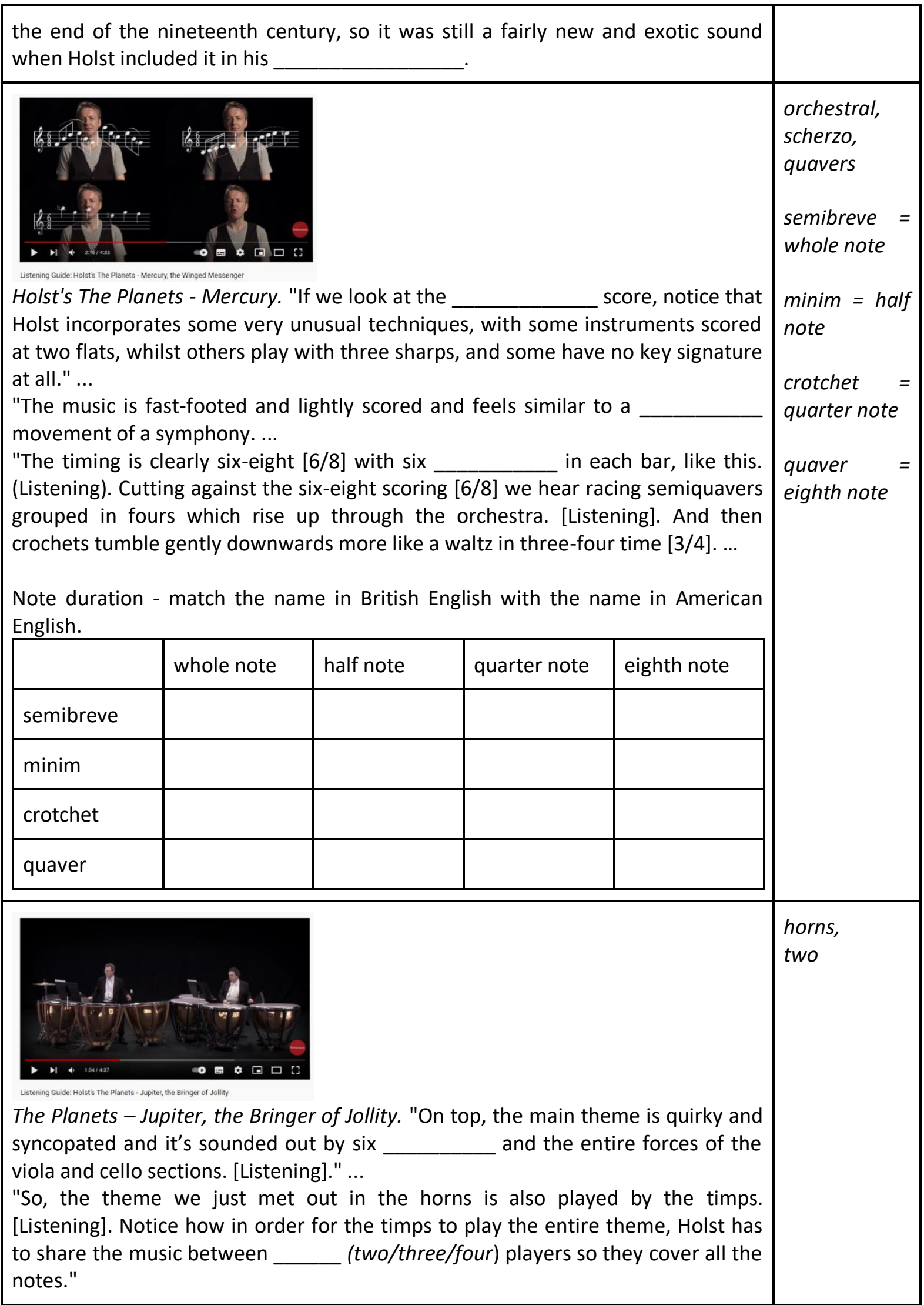




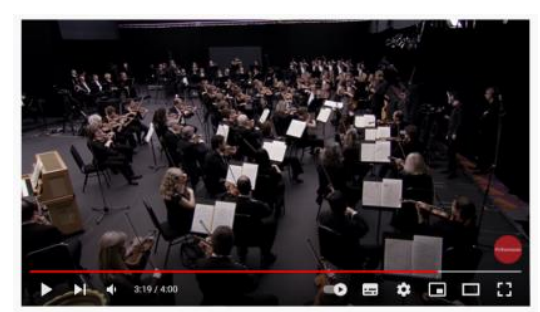

chords, trombones

The Planets - Saturn, the bringer of old age. The opening bars of 'Saturn' have been described as a ticking clock with flutes and harps gently rocking back and forth between two . Underneath, Holst scores a slow and expansive main theme in the double basses and it brilliantly paints a picture of time slowly passing by. ...

This is followed by a solemn procession, and I don't think it's specifically a funeral march, but it's worth noting that the bass theme is taken out by the (trombones/pianos/drums) who throughout history have had a very strong association with sacred music.

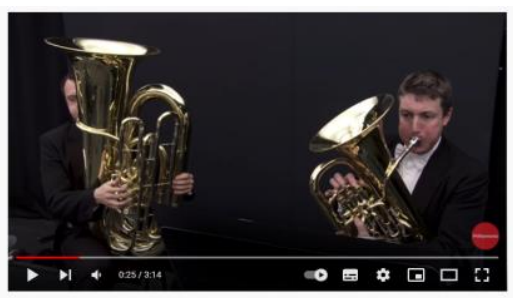

The Planets - Uranus, the Magician. Hello, my name is Paul Rissmann and I'm going to guide you through the movement of 'The Planets - Uranus, the Magician' whose arrival is announced by a fanfare of trumpets, trombones and timpani. [Listening]....

"The planet Uranus moves on a completely unique access as it rotates on its side and perhaps the unconventional motion is represented here by this bombastic lolloping (march/waltz/polka/tango) tune."

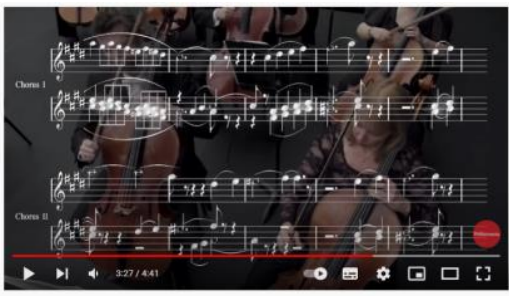

The Planets - Neptune: the mystique.

"I think that Neptune's orchestration is the most exquisite in the entire suite. Every choice is carefully calculated and perfectly balanced, such as the bass flute casting a dark shadow underneath the regular concert flute or the magical shimmer that radiates from the harps. This adventurous orchestration produced music which today, almost one hundred years later, still feels futuristic. But I guess that connection is reinforced by the fact that Hollywood composers have clearly been influenced by Holst. It's certainly not difficult to imagine this 
music as a soundtrack to your favourite Sci-Fi movie. [Listening]. ...

"In addition to the lavishly expanded orchestra on stage, Holst also requires that we have a ladies chorus cunningly concealed from the The scoring of a ladies choir into the final bars of The Planets is one of the most extravagant but most brilliant moments in the history of music and you can't help to admire Holst to have been brave enough to do it. [Listening]." ...

"Throughout the suite, he has explored the influence that planets have on our daily life, so what better way than to complete this extraordinary journey than with the sound of the human [Listening]."

The music-related activities of singing, listening to music or performing music are considered especially useful and beneficial for emotional wellbeing, obtaining feelings of enjoyment, maintaining a good mood and getting distracted from the crisis (Martínez-Castilla et al. 2021), through the use of easily accessible digital media technologies (radio, TV, online media, mobile apps, etc.). Acknowledging the fact of fast distribution of information and content online, in this course, students were introduced to the idea of "the lesson gift-bag" that included additional readings and links to videos in English connected to performances or concert live streams, music scores, etc. For example, in week 4 (lessons 7\&8) thematically focused on "Music Arts and Music School: Music Culture/History of Music/Music Appreciation (listening to music)", it included a voluntary music activity of listening, playing, singing and sharing of a choral music piece (solo or in group online) titled "Sing Gently" by Eric Whitacre, created in response to the COVID-19 pandemic lockdown. Students were provided with the lyrics, a link to the video recording of the performance ("Virtual Choir 6") and a copy of a music score as a pdf. During that particular period, students were daily exposed to hearing about the loss of many people in the world or local community, and the idea of including this particular choral piece in the course was intentionally offered as an additional activity, to provide students with "new" music, music that "might give some small measure of comfort for those who need it, and that might suggest a way of living with one another that is compassionate, gentle, and kind" (Whitacre, 2020). As it was a "gift" to which students replied with expressing thanks, usually using emoticons, the impact on wellbeing was not "measured".

\section{The students' voices}

In the following part, an example of a homework activity connected to the use of digital media is presented. Content and vocabulary from the lesson are approached but with a different task of writing a short text (5 to 10 sentences) commenting on an interesting or important topic or topics from the assigned video, e.g. Video documentary that goes behind the scenes at the Philharmonia Orchestra's "Universe of Sound" project. In the following part, the statements of students related to wellbeing in general and linguistic wellbeing were identified (emotions, individual reactions to music, musicians, performers, video content and technology used).

(Comment 1) This project was made back in 2013. I find it very interesting, especially the fact that they gave the audience an opportunity to experience how playing instruments actually feels like. There are standard instruments that they were using in "The Planets", such as the violin, bass, flute, horn, trombone, and there are some unusual, such as the glockenspiel, snare drum, triangle, and double tubular bells. Each of these instruments has their own special sound, but all together they sound way much better and stronger. People in England are full of ideas and inspirations! This project surely was a big challenge for each of those hard-working people, but together they did a great thing!

(Comment 2) For me it is hard to say what is interesting in this video. The whole story about the 
orchestra is amazing! Musicians and instruments are wonderful. This was completely new for me that there is such a great production of 37 cameras, $360 \mathrm{~d}$ kw light, and little action cameras that people can use to record themselves while they are playing.

(Comment 3) I really liked the way they combined technology with the orchestra. People without education in music and who don't have the opportunity to be part of the orchestra can see the whole process. I think simulations in this project are really good and innovative, something I personally have not seen before. This is a tremendous project and I hope that future projects will build upon the existing, as far greater and better.

(Comment 4) This video presents many interesting things related to the Philharmonia Orchestra. It shows how music technology has advanced. It was interesting to see the Museum of Science, which has rooms with sections in which are shown the videos of the orchestra. I like the part with the women choir of eighteen singers singing in church. That church has good acoustics. Philharmonia Orchestra offers a unique interactive element for practicing conducting by following the patterns on the screen. I like this video because people who work in the Philharmonia Orchestra love their dynamic work.

(Comment 5) "The Making of Universe of Sound" - what a brilliant idea! I am fascinated! I would definitely recommend it. An outstandingly numerous team of artists decided to make a gigantic (enormous) installation by combining classical music and science. The performance attracted a lot of people who were experiencing video pictures that they could actually walk into and interact with. In my opinion, the most spectacular fact is the number of people who were engaged in such a colossal project. Musicians, including music players and singers, composers, music supervisors, GoPro operators, sound engineers, lead editors, interactive developers, office staff...and a lot more. I wonder how it was possible to organize them at all? It looks like a real jigsaw puzzle to me where each individual piece had to be perfectly arranged! It is the most stimulating show I have ever seen. Don't you agree that that's really inspiring for us, young musicians?

(Comment 6) They made a project with the help of music and technology. They combined music with science and the technical possibilities of recording. Using the latest technology and digital objects (cameras and sound systems) they tried to bring people closer to what it's like to play in an orchestra. They recorded the orchestra with 45 microphones and 37 cameras, which they divided into sections - strings, winds, percussion, choir, and finally combined and assembled everything that was recorded. The whole project seems very interesting to me and I wish I could visit it!

(Comment 7) I personally find the whole idea and the concept mind-blowing and brilliant! All participants were extremely dedicated and paid attention to every single detail, such as the audio and camera angle. I really liked how the digital posters were made to present the orchestra instruments and music in a completely unconventional way. This project has shown people who are not in the "musical world", how playing in an orchestra really feels like. It attracted people who usually wouldn't go to a classical music concert or a museum, and showed them how it really looks like, from the artistic point of view.

(Comment 8) The whole project is fascinating, it is so unusual and unreal. It is amazing how they used so much equipment. I like the dedication of all workers, as they look like a big family. It is a new way to help classical music "stay alive", to color it with new digital technology. I find it very interesting that anyone can try conducting and playing musical instruments, like playing video games. 
In the course design, special emphasis was also put on the implementation of contemporary video materials, especially in the form of vlogs by young professional musicians, e.g. pianist Tiffany Poon (YouTube), offering learners quality input language that can be reused in creative ways and help students to improve their communication in speaking and writing. It is important to underline also the potential role of creativity in cultivating and supporting linguistic wellbeing. The aim of these activities was to empower personal creative expression in a foreign language using comments sections, as a space that offers the possibility to revisit, edit and receive feedback from others. For example, to the questions "What was your first experience with classical music?" and "What is classical music to you? What does it mean to you?", students answers included comments such as:

(Q1) "What was your first experience with classical music?"

(Comment 1) My first experience with classical music was going to the theater with my family, where we listened to Emanuel Pahud, the best flute player in the world, where my desire for music was born.

(Comment 2) I do not remember my first experience, but I do know that I was very young because my grandmother used to bring me to the theater with her, but I don't really remember my encounters with classical music before music school.

(Comment 3) Probably when my older brother started primary musical school.

(Comment 4) My first touch with classical music was when I was really young, because that genre of music is a genre that my family is listening to, and it's kinda normal that I started to listen to it too.

(Comment 5) I first experienced classical music when my mum took me to a concert when I was 5 years old. My aunt played the violin there and my mum's intention was to get me to like the violin and perhaps start playing it in the future. I honestly didn't like the violin, but I fell in love with the flute and I have been playing it ever since.

(Q2) What is classical music to you? What does it mean to you?

(Comment 1 ) For me that's my passion and hopefully my future profession.

(Comment 2) It relaxes me and I like to play it on my instrument.

(Comment 3) Classical music plays a very important role in my life and it makes it a hundred times better. It's relaxing and, at the same time, it reduces tension or anxiety. When I'm sad or nervous, classical music is my escape from reality. In my opinion, people all around the world should listen to classical music because it offers a lot of inspiration and pleasure.

As the "achievement of communicative purposes increasingly relies on the employment of not only linguistic resources but also digital and multimodal resources" (Xia 2020: 156), the choice of assigned video materials was also (re)evaluated through commenting as a classroom activity. For example, for all the videos students presented in class, the reactions of students in the comments sections were very open and informative, as in the following section:

1. "What is classical music to you and me? Tiffany Vlogs"

"I like it a lot because it is about people's opinion on classical music which varies from person to person as we are all different and it means different things to us" (comment 1);

"In this video, Tiffany is talking about other people's first experiences with classical music. She is comparing their opinion with her own. I like her passion and enthusiasm. I totally agree with her that classical music, both playing and listening to it, is the way of life." (comment 2);

"Tiffany wanted to show us classical music in her own way, to explain to us how classical music affects people" (comment 3),

"I really liked her way of thinking. Classical music is something special that awakens a lot of feelings in a person. Today, it is difficult to find such a good video on this topic"(comment 4).

2. Insert from the movie "A Song to Remember" - Chopin \& Liszt: 
"I like Chopin's Polonaise op.53 in this video. The video is interesting." (comment 1);

"It is really an interesting clip because it shows Chopin's and Liszt's relationship, as Liszt is playing Chopin's unfinished piece but nobody in the room knows that he is the composer. It is a bit funny, too." (comment 2);

"In this video, I really love the music. It made the biggest impression on me. The most interesting moment was when two famous composers, Liszt and Chopin, met and played together. It was amazing!"(Comment 3),

"This video was very exciting to watch. (...)" (Comment 4).

3. "The Cat Concerto" - Hungarian Rhapsody No.2 - Franz Liszt - piano - Canacana:

"The video is very nice." (Comment 1 );

"Inspiring."(Comment 2),

"I very much like the idea that this music is used in the cartoon Tom and Jerry. I have to say that I didn't know that and actually it brings back childhood memories..."(Comment 3);

"Playing the piano in the video is magnificent. I like her passion and the way she plays it. The idea of combining her playing with cartoon scenes is very interesting and inspiring. (Comment 4);

"Tom and Jerry are a very familiar cartoon to all of us. It's a very nice way to play through this cartoon." (Comment 5),

"Music is special precisely because it can be shown in any way we want, just like this one." (Comment 6).

4. "Rick Steves - Salzburg and Surroundings":

"This video explains about Salzburg and Mozart. Salzburg is a very beautiful town."(Comment 1); "It is Mozart's birthplace and the presenter walks us through the great composer's life and even the dances of this historical period. Magnificent! (...) I would like to visit Salzburg one day."(Comment 2);

"Rick Steves is introducing Salzburg, the birthplace of Mozart. He is talking about some of the most important sights there, beautiful nature, people and entertainment. The funniest thing for me there would be trying the summer bobsledding." (Comment 3);

"This video was the most beautiful for me because Mozart is one of my favourite composers. At the beginning of the video, I really like the clothes that people are dressed in. The video tells us a lot of interesting things about Salzburg. It seems like a very beautiful city to live in. I am just thrilled with the video." (Comment 4).

5. Inside Steinway's Vault: Most Exclusive (\& Expensive) Piano Showroom, Tiffany Vlogs \#90:

"I'm surprised how beautiful pianos are."(Comment 1 );

"I think that it is the best piano showroom I have ever seen, with all the colours and effects. It is in New York City. Tiffany is being given a tour and she likes what she hears about how it was established. She can even try the piano, so I envy her a bit! The pianos there are very special."(Comment 2);

"This is Tiffany's first visit to Steinway's New York factory. She was delighted. Everything there was so exclusive and, at the same time, expensive (pianos, candles, atmosphere...). There she played on all the really nice pianos and she was fascinated by them. Every piano was special because of something (paintings, crystals...)."(Comment 3 );

"This video is very exciting. I really like the way she logs in. She showed us her playing and escorted us through one of her days in New York."(Comment 4);

"This kind of presentation of classical music is the closest to us young people."(Comment 5);

"I liked her addressing the people who follow her the most. These videos are very interesting."(Comment 6). 


\section{Final remarks}

As noted by Sheppard \& Broughton (2020), "historically, the performing arts have been vitally important not only to individuals in ill-health, but also an important contributor to the wellbeing and health maintenance of individuals without preexisting health, behavioral, or social issues". The aim of this research was to focus on the intersection of language and music education, specifically, pedagogical uses of language focused on classical music to support the linguistic wellbeing of students. The research was conducted during a six-week of English as a foreign language course online (12 lessons) with 30 second-year students of Music Performance at the Secondary Music School in Serbia during the remote teaching and learning period in 2020. The research implemented a fully online learning model (six 90minute asynchronous lessons). The interconnected music and language activities appear to be highly engaging and enjoyable to students, indicating that they might be positively motivated to continue following and researching these channels and artists, and their future posts, to continue the ongoing language interaction and participation in the global online music community. The objective of publishing this research would be to share this unique teaching and learning experience, attempting at triggering the sensation of linguistic wellbeing in an EFL and partly ESP setting.

The qualitative results obtained from the research and presented in this paper, suggest that the course had a positive impact on the learners, in terms of their linguistic in class reactions and interactions in English (expressing the experience of pleasure, satisfaction and self-realization in learning the language, "hearing" students' voices). Adopting the idea that "linguistic wellbeing as a fundamental pedagogical concept" was "awakened by the pandemic" (Daszkiewicz 2021), this research contributes to both the pedagogical and linguistic literature as it focused on the contribution of music and language (focused on classical music) to the linguistic wellbeing of students of Music Arts as future professional musicians, "currently underrepresented in research on wellbeing" in general (Kiernan, Davidson \& Oades 2020: 4). Therefore, in the following period, the aim would be to further research the intersections of language, digital media technologies and pedagogy, specifically the role of music on linguistic wellbeing in different language education contexts.

\section{Acknowledgements}

In 2020/2021 the research activity of Dr Sladjana Maric, Research Associate at the Faculty of Philosophy (University of Novi Sad) was funded by the Ministry of Education, Science and Technological Development of the Republic of Serbia.

\section{References}

Brown, J. D. \& Coombe, C. (2015). The Cambridge Guide to Research in Language Teaching and Learning, Cambridge University Press.

Burns, A. (2010). Doing Action Research in English Language Teaching: A Guide for Practitioners, Routledge.

Burns, A. (2013). Innovation through action research and teacher-initiated change, in: K. Hyland \& L.L.C. Wong (Eds.), Innovation and change in English language education (pp. 90-105). https://doi.org/10.4324/9780203362716

Coghlan, D. \& Brydon-Miller, M. (2014). The SAGE encyclopedia of action research, London SAGE Publications Ltd doi: 10.4135/9781446294406

Cohen, L., Manion, L. Morrison, K. (2018). Research Methods in Education, 8th edition, Routledge.

Daszkiewicz, M. (2021). 4th ERL Session - May 5-6, 2021 "Linguistic well-being (before, during, and after the pandemic)", http://educationalroleoflanguage.org/erl-events/erl-online-sessions-talks/ 
Flew, T., Kirkwood, K. (2020). The impact of COVID-19 on cultural tourism: art, culture and communication in four regional sites of Queensland, Australia. Media International Australia, 178(1),16-20. doi:10.1177/1329878X20952529

Gale, S., Moore, Z., Ruddy, S. (2013). The Planets 2014 Youth Concert Teacher Resource Materials. Ann Arbor Symphony Orchestra.

Hessel, G., Talbot, K. R., Gruber, M.-T., Mercer, S. (2020). The Well-being and Job Satisfaction of Secondary CLIL and Tertiary EMI Teachers in Austria. Journal for the Psychology of Language Learning, 2(2), 73-91. Retrieved from https://ipll.org/index.php/journal/article/view/33

Hutchinson, T., Waters, A. (1987). English for Specific Purposes: A learning-centred approach, Cambridge University Press.

Kiernan, F., Davidson, J.W., Oades, L.G. (2020). Researching creativity and wellbeing: Interdisciplinary perspective. International Journal of Wellbeing, 10 (5), 1-5.

King, K. A., Lai, Y-J., May, S. (Eds). (2017). Encyclopedia of Language and Education: Research Methods in Language and Education, Third Edition, Springer.

Maclntyre, P.D., Gregersen, T., Mercer, S. (2020). Language teachers' coping strategies during the Covid19 conversion to online teaching: Correlations with stress, wellbeing and negative emotions, System, 94, 1-13. https://doi.org/10.1016/i.system.2020.102352.

Martínez-Castilla, P., Gutiérrez-Blasco, I. M, Spitz, D. H., Granot, R. (2021). The Efficacy of Music for Emotional Wellbeing During the COVID-19 Lockdown in Spain: An Analysis of Personal and ContextRelated Variables. Frontiers in Psychology, 12, (Article Number) 647837, p. 1-15. doi: 10.3389/fpsyg.2021.647837

McDonough, J., Shaw, C., Masuhara, H. (2013). Materials and Methods in ELT: A Teacher's Guide, Third Edition, A John Wiley \& Sons, Ltd., Publication.

Mercer, S. (2020). The wellbeing of language teachers in the private sector: An ecological perspective. Language Teaching Research, 1-24. doi: 10.1177/1362168820973510.

Mercer, S. (2021). An agenda for well-being in ELT: An ecological perspective. ELT Journal, 75(1), 14-21.

Resnik, P., Dewaele, J.M. (2021). Learner emotions, autonomy and trait emotional intelligence in 'inperson' versus emergency remote English foreign language teaching in Europe. Applied Linguistics Review, (Article Number) 000010151520200096. https://doi.org/10.1515/applirev-2020-0096.

Sheppard, A., Broughton, M. C. (2020). Promoting wellbeing and health through active participation in music and dance: a systematic review, International Journal of Qualitative Studies on Health and Wellbeing, 15(1): 1-19. doi: 10.1080/17482631.2020.1732526

Shin, S., Mercer, S., Babic, S., Sulis, G., Mairitsch, A., Jin, J., King, J. (2021). Riding the happiness curve: The wellbeing of mid-career-stage language teachers. The Language Learning Journal. 1-14. https://doi.org/10.1080/09571736.2021.1979632

Sulis, G., Mercer, S., Mairitsch, A., Babic, S., Shin, S. (2021). Pre-service language teacher wellbeing as a complex dynamic system, System, Vol. 103, (Article Number) 102642 p. 1-12. https://doi.org/10.1016/j.system.2021.102642

Wallace, M. J. (1998). Action research for language teachers. Cambridge teacher training and development. Cambridge University Press.

Whitacre, E. (2020). "Sing Gently" (Music score - Notes of the composer) https://www.jwpepper.com/Sing-Gently/11219607.item\#.YZFdVGDMLIV

Xia, S. A. (2020). Genre Analysis in The Digital Era: Developments and Challenges, ESP Today, 8(1): 141159, https://doi.org/10.18485/esptoday.2020.8.1.7. 